RU Применение образовательного квеста как формы контроля на занятиях по русскому языку как иностранному

\begin{abstract}
Антипова И. А., Сидорова О. Ю. теоретического материала.

\section{EN Using the Educational Quest as a Form of Control during Russian as a Foreign Language Classes}

Аннотация. Цель исследования - показать целесообразность применения творческой формы контроля полученных знаний, умений и навыков в процессе обучения курсантов - иностранных военных специалистов публицистическому стилю. В статье рассматриваются особенности применения образовательного квеста как формы контроля на занятиях по русскому языку как иностранному в Военном университете на примере изучения публицистического стиля. Научная новизна исследования выражается в том, что образовательный квест представлен как нетрадиционная эффективная форма контроля и проверки знаний, умений и навыков владения русским языком иностранными военными специалистами. Использование образовательного квеста в форме контроля полученных знаний, умений и навыков обучающихся направлено на повышение процента качества усвоения

\begin{abstract}
Antipova I. A., Sidorova O. Y.
Abstract. The purpose of the research is to show the feasibility of using a creative form of control of the acquired knowledge, skills and abilities in the process of teaching the publicistic style to cadets foreign military specialists. The paper considers the features of applying the educational quest as a form of control during Russian as a Foreign Language classes at the Military University, using the study of the publicistic style as an example. Scientific novelty of the research lies in the fact that the educational quest is presented as an unconventional effective form of control and assessment of foreign military specialists' knowledge, skills and proficiency in the Russian language. The use of the educational quest in the form of control of students' acquired knowledge, skills and abilities is aimed at increasing the quality of theoretical material acquisition.
\end{abstract}

\title{
Введение
}

Продуктивные образовательные технологии занимают важное место в процессе обучения русскому языку как иностранному. В настоящее время трудно представить занятие по русскому языку без компьютерной презентации, интерактивной доски и электронного учебника. Все это помогает сделать процесс обучения интересным, понятным и коммуникативным. Неотъемлемой частью изучения любой темы или любого раздела дисциплины является проведение контроля, который осуществляется в разных формах. Помимо традиционных контрольных работ используются тестовые и игровые задания, образовательные квесты. Образовательный квест учебная игра-путешествие, которая предполагает общую игровую ситуацию (сюжет). Все элементы образовательного квеста подчинены общей учебной задаче. В процессе прохождения квестов курсанты выполняют разного рода задания, приобретают навыки групповой работы и самоорганизации (поэтому данная методика может оказаться очень полезной и для решения тех или иных воспитательных задач, стоящих перед педагогом). В образовательном процессе квест - специальным образом организованный вид исследовательской деятельности, для выполнения которой обучающиеся осуществляют поиск заданной преподавателем информации.

Образовательный квест как форма контроля описывается в работах А. В. Вавулиной, Е. Ю. Николенко (2017), Е. А. Волковой, И. А. Кузнецовой (2019), Г. А. Стародубовой, Е. В. Косолаповой (2020) в контексте обучения русскому языку носителей языка, региональному страноведению как составной части курса русского языка, русскому языку как иностранному на разных этапах обучения. Актуальность темы квеста обусловлена социальным заказом, исходя из которого система высшего образования должна развиваться: необходимо внедрять инновационные средства, технологии и методики, что позволит оптимизировать образовательный процесс.

Научная статья (original research article) | https://doi.org/10.30853/ped20220002

( 2022 Авторы. 000 Издательство «Грамота» (๔ 2022 The Authors. GRAMOTA Publishers). Открытый доступ предоставляется на условиях лицензии СС ВY 4.0 (open access article under the CС BY 4.0 license): https://creativecommons.org/licenses/by/4.0/ 
Образовательный квест является инновационной формой контроля для повышения мотивации иностранных военных специалистов, в связи с чем нужно раскрыть теоретические и практические аспекты создания квеста.

Для достижения поставленной цели исследования требуется решить следующие задачи:

- раскрыть сущность понятия «образовательный квест» в педагогической науке;

- представить перечень заданий образовательного квеста, направленного на повторение изученного теоретического материала по русскому языку как иностранному;

- изложить результаты внедрения образовательного квеста как формы контроля с целью повышения качества усвоения полученных знаний и умений в Военном университете.

Для решения поставленных задач были использованы следующие методы исследования:

- теоретические: анализ учебно-методической литературы;

- эмпирические: проведение констатирующего этапа эксперимента с целью определения степени усвоения полученных знаний и умений, качественно-количественный анализ полученных экспериментальных данных и их статистическая обработка.

Теоретическая база исследования. В научной литературе квест рассматривается как технология в работах Г. Ш. Ахметовой (2018), Е. А. Игумновой, И. В. Радецкой (2016), И. Ю. Мишоты (2018), Е. В. Рублевой (2019); как способ активизации речевой деятельности - в трудах Е. А. Волковой, И. А. Кузнецовой, М. С. Наймушиной (2018). Квест как форма контроля упоминается в работе Е. А. Волковой, И. А. Кузнецовой (2019), но в качестве проверки основ регионального страноведения, а не темы или раздела основного курса обучения иностранному языку.

Практическая значимость данного исследования заключается в том, что:

- предложена форма контроля полученных знаний и умений;

- данная форма контроля внедрена в образовательный процесс Военного университета;

- результаты исследования использованы в образовательной деятельности при создании последующих квестов, при проведении научно-практических конференций.

\section{Сущность понятия «образовательный квест» в педагогической науке}

Применение образовательного квеста направлено на повышение мотивации и интереса обучающихся к изучению русского языка как иностранного, развитие коммуникативной компетенции и совершенствование умений продуцирования письменных и устных текстов. В методической литературе существует немало определений понятия квеста.

С. А. Осяк и соавторы (Осяк, Султанбекова, Захарова и др., 2015) характеризуют образовательный квест как «специальным образом организованный вид исследовательской деятельности, для выполнения которой обучающиеся осуществляют поиск информации по указанным адресам (в реальности), включающий и поиск этих адресов или иных объектов, людей, заданий и пр.» (с. 157). Ученые подчеркивают исследовательский характер квеста, что сближает квест с научной деятельностью.

О возможности осуществления дифференциации процесса обучения с помощью квеста говорят Ю. В. Калугина и А. Р. Мустафина (2016), которые определяют квест как «одну из нетривиальных интерактивных форм обучения иностранным языкам» (с. 253) и обращают внимание на то, что квест позволяет реализовать индивидуализацию обучения. Действительно, использование квеста помогает развить у курсантов навыки осознанной самостоятельной работы, а также индивидуализировать процесс обучения (выбрать комфортный темп работы, получить обратную связь).

Говоря о сущности образовательного квеста, Е. В. Анисимова, Е. А. Волкова, А. Ю. Ковалева (2021) утверждают, что «образовательный квест - это современная интерактивная технология, которая включает в себя набор заданий, охватывающих какую-либо тему (проблему), способную заинтересовать участников, нацеленных на получение и запоминание информации, приобретение опыта работы в команде и формирование базовых компетенций» (с. 21). Авторы говорят о наборе заданий по какой-либо теме, но не акцентируют внимание на том, что благодаря итоговому заданию, логически вытекающему из предыдущих, реализуется цель квеста.

И. Н. Сокол (2014) считает, что «квест - это технология, которая имеет четко поставленную дидактическую задачу, игровой замысел, обязательно имеет руководителя (наставника), четкие правила и реализуется с целью повышения у обучающихся уровня знаний и умений» (с. 138). Сочетание игровой технологии и четкой проблемной ситуации - один из основных элементов образовательного квеста.

Е. А. Игумнова, И. В. Радецкая (2016) дают следующее определение: «образовательный квест - интегрированная технология, объединяющая идеи проектного метода, проблемного и игрового обучения, взаимодействия в команде и ИКТ; сочетающая целенаправленный поиск при выполнении главного проблемного и серии вспомогательных заданий с приключениями и (или) игрой по определенному сюжету». Представленная дефиниция характеризуется широким охватом технологий, которые можно выявить в образовательном квесте.

В данной статье мы будем опираться на определение образовательного квеста, предложенное И. Н. Сокол. Для того чтобы квест стал одной из форм контроля по определенной теме или разделу, преподавателю необходимо достаточно четко проработать главную задачу квеста и систему игровых заданий. Обучающиеся должны понимать «маршрут» следования квеста и главный результат, к которому они приходят.

Таким образом, в методической литературе образовательный квест рассматривается как современная интерактивная форма обучения, включающая в себя игровой компонент и проблемную задачу, которую необходимо решить. Образовательный квест развивает личность обучающегося, способствует большей заинтересованности в получении знаний, умений и навыков, и, как следствие, лучшему усвоению материала. 
Перечень заданий образовательного квеста, направленного на повторение изученного теоретического материала по публицистическому стилю

В качестве примера приведем перечень заданий образовательного квеста, направленного на повторение изученного теоретического материала по темам «Стилевые черты и языковые особенности публицистического стиля», «Газетно-информационный подстиль», «Собственно публицистический подстиль», «Средства речевой выразительности», «Ораторская речь». Целевую аудиторию составляют курсанты 3 курса, обучающиеся по юридической специальности, из стран дальнего зарубежья с уровнем владения русским языком в пределах первого сертификационного уровня (ТРКИ-I/B1). В начале занятия преподаватель озвучивает главный вопрос квеста, проводит инструктаж по выполнению заданий.

Преподаватель: Слово - это средство общения, с которым надо уметь обращаться любому человеку. Представьте, что вы поднимаетесь по высокой лестнице в зале с целью оказаться на самой верхней ступеньке и выступить перед собравшимися зрителями. Вам предстоит пройти через некоторые испытания и ответить на поставленный вопрос «Какое место занимает слово в публицистическом стиле?». В случае затруднений будет возможность обратиться к подсказкам.

Комментарий: Задание 1 направлено на выявление признаков мысли, определение связи слова и мысли; развитие речемыслительных умений.

Задание 1. Подумайте, почему мысль - корень публицистики? Чем обладает мысль? В этом вам помогут приведенные ниже цитаты.

- Мысль - корень публицистики. Хорошо пишет не тот, кто хорошо пишет, а тот, кто хорошо думает.

- Смелость бывает разная. И я думаю, одна из ее высших форм - смелость мысли (Анатолий Аграновский - известный советский журналист, публицист, писатель, прозаик, певец и кинодраматург).

Комментарий: Целью Задания 2 является актуализация знаний по теме «Стилевые черты и языковые особенности публицистического стиля», выявление оценочной лексики. Выполнив данное задание, обучающиеся становятся на один шаг ближе к цели.

Задание 2. Как можно выразить эмоциональность в публицистике? Вы можете привести примеры из приведенного ниже текста (в статье приводится фрагмент текста).

«- Георгий Константинович Жуков - один из тех, кто внес наивысший вклад в победу нашей страны над фашистской Германией в Великой Отечественной войне. Его слава была, есть и останется всенародной, отметил заместитель главнокомандующего Сухопутными войсками генерал-лейтенант Александр Матовников. - Кроме того, маршал Жуков подписал акт о капитуляции фашистской Германии, принимал Парад Победы в июне 1945 года.

Также генерал-лейтенант Александр Матовников подчеркнул, что для современных Сухопутных войск маршал Г. К. Жуков важен и тем, что он первый в истории нашей армии стал главнокомандующим Сухопутными войсками» (Алексеев, 2021).

Дополнительные вопросы:

- О каком событии говорится в этом тексте?

- К какому стилю принадлежит данный текст?

Комментарий: Выполнив Задание 3, курсанты вспомнят теоретический материал по теме «Газетноинформационный подстиль».

Задание 3. Каким образом реализуются две основные функции публицистического стиля: информационная и воздействия? Для иллюстрации своих мыслей вы можете использовать фрагмент видео, посвященный открытию памятника маршала Советского Союза А. М. Василевского на Фрунзенской набережной в Москве.

Дополнительные вопросы:

- Что нового вы узнали из видео? Составьте заметку по материалам видео.

Комментарий: Задание 4 направлено на выявление средств речевой выразительности, которые входят в оценочный пласт лексики.

Задание 4. Вы знаете, что текст оказывает воздействие на аудиторию. Скажите, каким образом оно может осуществляться? Найдите ответ в приведенном тексте (в статье приводится фрагмент текста).

«Товарищи солдаты и матросы, сержанты и старшины, прапорщики и мичманы, офицеры!

Уважаемые ветераны Великой Отечественной войны, боевых действий и военной службы!

23 февраля в нашей стране отмечается День защитника Отечества. Этот по праву ставший всенародным праздник объединяет всех, кто посвятил свою жизнь ратной службе, кому небезразлична судьба страны, для кого защита Родины - это дело чести.

Великие подвиги и победы многих поколений русских воинов, их мужество, доблесть и отвага вызывают особую гордость у нашего народа. Важно хранить и приумножать героические традиции легендарных предшественников, чтить их славные свершения.

МИНИСТР ОБОРОНЫ РОССИЙСКОЙ ФЕДЕРАЦИИ

генерал армии

С. Шойгу» (Министр обороны..., 2019). 
Дополнительные вопросы:

- В каких лексических единицах реализуется тема патриотизма?

Комментарий: Выполнение Задания 5 позволит курсантам вспомнить материал по теме «Средства речевой выразительности».

Задание 5. Разгадайте кроссворд, заполнив его средствами речевой выразительности. Из выделенных букв составьте слово.

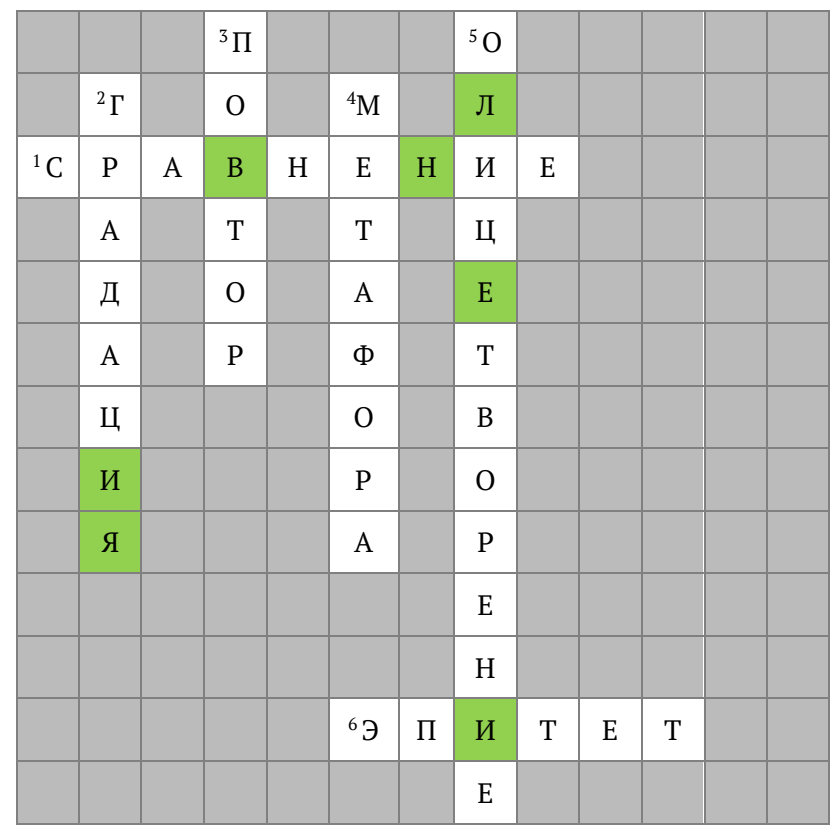

По горизонтали:

1. Берег правый, как стена...

(А. Твардовский)

6. С первых дней годины горькой, В тяжкий час земли родной

(А. Твардовский)
По вертикали:

2. На войне, в пыли походной, В летний зной и в холода, Лучше нет простой, природной Из колодца, из пруда, Из трубы водопроводной, Из копытного следа, Из реки, какой угодной, Из ручья, из-подо льда, Лучше нет воды холодной, Лишь вода была б - вода.

(А. Твардовский)

3. Переправа, переправа!

(А. Твардовский)

4. Здесь уж те сошлись, должно быть, Кто не в силах побороть Заседаний вкус особый...

(А. Твардовский)

5. Бой идет святой и правый

(А. Твардовский) (https://rustih.ru/aleksandr-tvardovskij).

Подсказка. Синонимы выделенного слова: воздействие, сила, действие.

Комментарий: Целью Задания 6 являются развитие умений выразительного чтения, психологическая разрядка.

Задание 6. Как нужно обращаться со словом, чтобы оно помогало автору? Вы можете прочитать стихотворение Давида Самойлова (https://rustih.ru/david-samojlov-slova) и ответить на вопрос.

Люблю обычные слова,

Как неизведанные страны.

Они понятны лишь сперва,

Потом значенья их туманны.

Их протирают, как стекло,

И в этом наше ремесло.

Комментарий: Задание 7 является подготовительным к созданию воздействующей речи. В ходе его выполнения курсанты тренируют ассоциативное мышление. 
Задание 7. Вы поняли, что слово - это не только инструмент познания, но и... (продолжите фразу).

\begin{tabular}{|l|l|}
\hline Продолжите предложения и найдите пропущенное слово. & Вариант выполнения: \\
Слово - это о... & Слово - это образ мысли. \\
Слово - это ц... & Слово - это центральная единица языка. \\
Слово - это е... & Слово - это единица языка. \\
Слово - это н... & Слово - это набор букв. \\
Слово - это к... & Слово - это ключ к познанию. \\
Слово - это а... & Слово - это абстрактное существительное. \\
\hline
\end{tabular}

Подсказка: прочитайте ту часть предложения, которую вы продолжали сверху вниз, тогда у вас получится искомое слово.

Дополнительные вопросы:

Какой вывод вы можете сделать? Назовите функции слова.

Комментарий: Итоговое Задание 8 направлено на создание воздействующей речи и выступление с ней; развитие творческих умений.

Задание 8. Составьте воздействующую речь на свободную тему. В свой текст вы можете включать материалы заданий. Выступите с речью.

Таким образом, последовательное выполнение перечня заданий из представленного образовательного квеста позволяет иностранным военнослужащим вспомнить функции слова, повторить основной теоретический материал по публицистическому стилю, подготовить воздействующую речь и выступить с ней. Выполнение заданий квеста направлено на взаимосвязанное развитие всех видов речевой деятельности.

\section{Внедрение в образовательный процесс Военного университета образовательного квеста как формы контроля полученных знаний, умений и навыков с целью повышения степени усвоения изученного материала}

Гипотеза эксперимента: если использовать в качестве контроля полученных знаний, умений и навыков образовательный квест, то повысится уровень применения полученных знаний, умений и навыков обучающихся в соответствии с коммуникативной установкой преподавателя.

Эксперимент проводился в группах курсантов из стран дальнего зарубежья (30 человек). Возраст участников эксперимента: 22-24 года. Направление подготовки: «Правовое обеспечение национальной безопасности». База проведения эксперимента: Военный университет Министерства обороны Российской Федерации. Курсанты были распределены по 3 группам, в каждой из которых - по 10 человек из стран дальнего зарубежья: Лаос, Эсватини, Вьетнам. Эксперимент проводился после изучения материала, посвященного публицистическому стилю, в два этапа: на первом этапе обучающиеся выполняли контрольную работу, тест и перечень заданий образовательного квеста, представленного выше (два академических часа); на втором этапе курсанты продуцировали речь на тему «Роль слова в вашей будущей профессиональной деятельности» (четыре академических часа).

Первая группа выполняла традиционную контрольную работу, которая состояла из следующих заданий: 1) проанализировать текст и определить его стилевую принадлежность (в качестве доказательств привести примеры характерных черт и языковых особенностей); 2) выявить в тексте изобразительно-выразительные средства и назвать их; 3) составить заметку о каком-либо событии; 4) написать эссе по одной из предложенных тем: «Все проходит, да не все забывается» (Иван Алексеевич Бунин - русский писатель); «Наука - это организованное знание» (Герберт Спенсер - английский социолог и философ); «Судья - это говорящий закон, а закон - это немой судья» (Цицерон - римский политический деятель, оратор, философ); «Речь людей такова, какой была их жизнь» (Сенека - римский философ, поэт и государственный деятель). Критерии выставления оценок: «отлично» - обучающийся выявляет стилевые черты и языковые особенности, приводит примеры, соблюдает все требования, предъявляемые к текстам заметки и эссе, уместно использует изобразительновыразительные средства; «хорошо» - обучающийся выявляет не все стилевые черты и языковые особенности, приводит примеры не ко всем положениям, в целом соблюдает требования, предъявляемые к тексту заметки и эссе, допускает незначительные нарушения норм русского языка; «удовлетворительно» - обучающийся испытывает затруднения при выполнении заданий, допускает нарушения норм русского языка, которые в целом не ведут к прекращению коммуникации; «неудовлетворительно» - обучающийся не справился с заданием.

Вторая группа работала над тестом, который состоял из 25 вопросов с выбором ответа и 2 практических заданий (составить заметку о каком-либо событии; написать эссе, используя предложенное введение). Например: 1. Определите вид тропа в следующих примерах: шелковые кудри, волнистые туманы, печальные леса, блестящий ответ. Варианты ответов: а) метафора; б) олицетворение; в) эпитет. 2. Какие части полной хрии выделял М. В. Ломоносов? Варианты ответов: а) введение, факты, доказательства, причины, противопоставление, сравнение, описание, заключение; б) введение, вступление, основная часть, факты, доказательства, описание, сравнение, заключение; в) приступ, парафразис, причина, противное, подобие или сравнение, пример, свидетельство, заключение. Критерии выставления оценок за тест: более 80\% - «отлично», 60-70\% - «хорошо», 50\% - «удовлетворительно», менее 50\% - «неудовлетворительно». Критерии выставления оценок 
за практическую часть = критерии выставления оценок за контрольную работу. Обучающийся получает общую оценку за выполнение теста и практической части.

Представленный перечень заданий образовательного квеста был использован в качестве формы контроля полученных знаний, умений и навыков для третьей группы обучающихся. Критерии выставления оценок: «отлично» - обучающийся владеет информацией об особенностях текста публицистического стиля, соблюдает модели составления текстов, уместно использует изобразительно-выразительные средства; «хорошо» - обучающийся в целом владеет информацией об особенностях текста публицистического стиля, соблюдает модели составления текстов, допускает незначительные нарушения норм русского языка; «удовлетворительно» - обучающийся испытывает затруднения при выполнении заданий, допускает нарушения норм русского языка, которые в целом не ведут к прекращению коммуникации; «неудовлетворительно» - обучающийся не справился с заданием.

Затем курсантам всех групп было предложено творческое задание по составлению речи на тему «Роль слова в вашей будущей профессиональной деятельности». Обучающиеся составляли текст по изученной модели: приступ - парафразис - причина - противное - пример - подобие (сравнение) - свидетельство - заключение; затем выступали с речью. Критерии выставления оценок: «отлично» - обучающийся соблюдает все требования, предъявляемые к составлению речи, владеет риторическими средствами общения; «хорошо» - обучающийся в целом соблюдает требования, предъявляемые к составлению речи, в целом владеет риторическими средствами общения, допускает незначительные нарушения норм русского языка, в целом осуществляет речевой самоконтроль; «удовлетворительно» - обучающийся испытывает затруднения при выполнении задания, допускает нарушения норм русского языка, которые в целом не ведут к прекращению коммуникации, осуществляет речевой самоконтроль не в полной мере; «неудовлетворительно» - обучающийся не справился с заданием.

Результаты выполнения контрольных заданий: первая группа - 35\%, вторая группа - 25\%, третья группа - 40\%; результаты выполнения творческого контрольного задания: первая группа - 30\%, вторая группа - $15 \%$, третья группа - 55\%. Представленные диаграммы (см. Диаграмму 1, 2) позволяют увидеть динамику изменения показателей эффективности предложенной формы контроля.

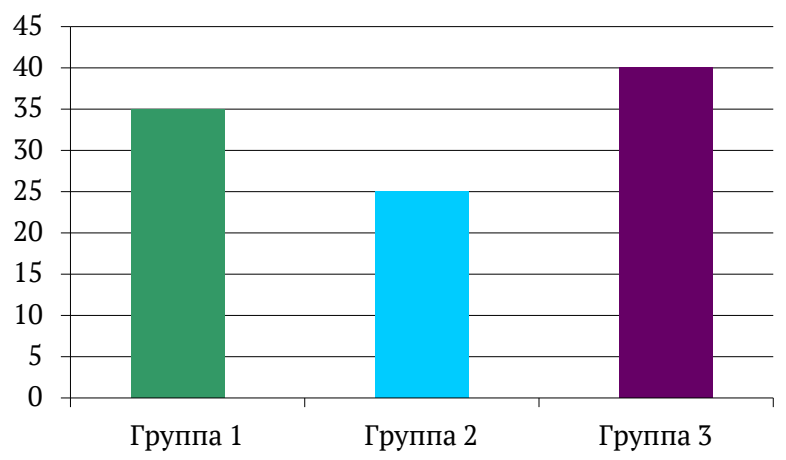

— Контрольная работа - Тест побразовательный квест

Диаграмма 1. Показатели эффективности применяемой формы контроля

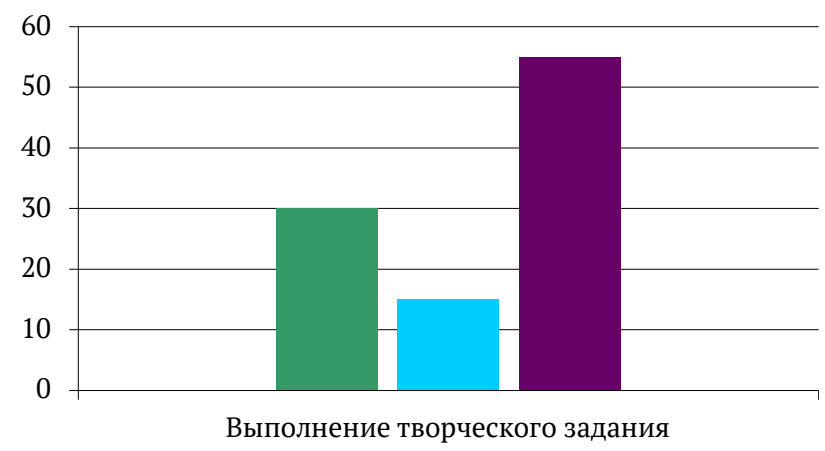

п Группа $1 \quad$ Группа 2 пруппа 3

Диаграмма 2. Эффективность применения образовательного квеста как формы контроля в целях развития творческих умений обучающихся по продуцированию текста

По сравнению с контрольной работой и тестом, являющимися формами контроля, проведение образовательного квеста повысило уровень применения полученных знаний, умений и навыков обучающихся в соответствии с коммуникативной установкой преподавателя. Эффективность предложенной формы контроля объясняется повышением мотивации не только к теоретическому, но и к практическому изучению основ публицистического стиля.

\section{Заключение}

Таким образом, можно сделать следующий вывод. Поставленная цель реализована при разработке перечня заданий для образовательного квеста как формы контроля на занятиях по русскому языку как иностранному. В ходе проведенного исследования изучена методическая литература, в которой большое внимание уделяется подготовке и проведению различных квестов.

Образовательный квест является достаточно эффективной формой осуществления контроля, так как благодаря игровому компоненту курсанты очень быстро вовлекаются в заданную ситуацию, активизируя мыслительную деятельность, тем самым показывая более высокий уровень развития знаний, умений и навыков владения русским языком как иностранным, чем при проведении стандартной контрольной работы или теста. Перечень заданий, входящих в образовательный квест, направлен на проверку усвоения теоретического и практического материала по публицистическому стилю. Последовательное выполнение заданий позволяет обучающимся собрать воедино языковой материал для продуцирования воздействующей речи. 
При осуществлении эксперимента и анализе полученных результатов выявлено, что процент хороших и отличных оценок, показывающий степень усвоения материала по публицистическому стилю, выше на 5\% по сравнению со стандартной контрольной работой и на 15\% - по сравнению с тестом. Результаты выполнения творческого задания при проведении квеста выше на 15\% по сравнению со стандартной контрольной работой и на $40 \%$ - по сравнению с тестом.

Перспективой дальнейшего исследования может являться рассмотрение видов образовательных квестов для проведения промежуточного и рубежного контроля среди обучающихся основных курсов.

\section{Источники | References}

1. Алексеев А. В память о гении ратного дела. 2021. URL: http://redstar.ru/v-pamyat-o-genii-ratnogo-dela

2. Анисимова Е. В., Волкова Е. А., Ковалева А. Ю. Образовательный квест как современная технология обучения иностранцев русскому языку // Азимут научных исследований: педагогика и психология. 2021. Т. 10. № 3 (36).

3. Ахметова Г. Ш. Использование квест-технологии как средства формирования творческих способностей студентов в процессе иноязычного образования // Теория и методика обучения иностранным языкам: традиции и инновации. Шатиловские чтения: сб. науч. тр. / Российский государственный педагогический университет им. А. И. Герцена; Санкт-Петербургский политехнический университет Петра Великого. СПб., 2018.

4. Вавулина А. В., Николенко Е. Ю. Использование технологии «веб-квест» при обучении РКИ на разных этапах обучения // Ученые записки Крымского федерального университета имени В. И. Вернадского. Филологические науки. 2017. № 4.

5. Волкова Е. А., Кузнецова И. А. Квест как форма контроля знаний регионального страноведения на уроках русского языка с иностранными студентами // Проблемы модернизации современного высшего образования: лингвистические аспекты: мат. V Междунар. науч.-практ. конф. (г. Омск, 24 мая 2019 г.). Омск: ОАБИИ, 2019.

6. Волкова Е. А., Кузнецова И. А., Наймушина М. С. Квест как способ активизации речевой деятельности иностранных студентов-медиков // Вестник Нижегородской государственной сельскохозяйственной академии. 2018. № 1 (17).

7. Игумнова Е. А., Радецкая И. В. Квест-технология в контексте требований ФГОС общего образования // Современные проблемы науки и образования. 2016. № 6. URL: http://www.science-education.ru/ru/article/view?id=25517

8. Калугина Ю. В., Мустафина А. Р. Анализ педагогического квеста как педагогической технологии // Преподаватель XXI века. 2016. № 4.

9. Министр обороны России поздравил военнослужащих и ветеранов с Днем защитника Отечества. 2019. URL: https://function.mil.ru/news_page/country/more.htm?id=12218536@egNews

10. Мишота И. Ю. Использование технологии веб-квест на занятиях иностранного языка в вузах // Научный вестник Московского государственного института физической культуры, спорта и туризма им. Ю. А. Сенкевича. 2018. № 6 (56).

11. Осяк С. А., Султанбекова С. С., Захарова Т. В., Яковлева Е. Н., Лобанова О. Б., Плеханова Е. М. Образовательный квест - современная интерактивная технология // Современные проблемы науки и образования. 2015. № 12. URL: http://www.science-education.ru/ru/article/view?id=20247

12. Рублева Е. В. Использование квест-технологии на занятиях по русскому языку как иностранному // Русский язык за рубежом. 2019. № 3.

13. Сокол И. Н. Классификация квестов // Молодий вчений. 2014. № 6 (09). URL: http://molodyvcheny. in.ua/files/journal/2014/6/89.pdf

14. Стародубова Г. А., Косолапова Е. В. Квест как средство организации контроля и проверки знаний студентов в сфере медийно-информационной грамотности и информационной культуры // Вестник Кемеровского государственного университета культуры и искусств. 2020. № 50.

\section{Информация об авторах | Author information}

RU Антипова Ирина Александровна ${ }^{1}$, к. филол. н.

Сидорова Ольга Юрьевна ${ }^{2}$, к. филол. н.

1,2 Военный университет Министерства обороны Российской Федерации, г. Москва

EN Antipova Irina Alexandrovna ${ }^{1}, \mathrm{PhD}$

Sidorova Olga Yurievna ${ }^{2}, \mathrm{PhD}$

1,2 Military University of the Ministry of Defense of the Russian Federation, Moscow

${ }^{1}$ irina-antipova.83@rambler.ru, ${ }^{2}$ future4you@yandex.ru

\section{Информация о статье | About this article}

Дата поступления рукописи (received): 10.12.2021; опубликовано (published): 28.02.2022.

Ключевые слова (keywords): образовательный квест; иностранные военные специалисты; русский язык как иностранный; форма контроля; публицистический стиль; educational quest; foreign military specialists; Russian as a Foreign Language; form of control; publicistic style. 